\title{
$\alpha$-Allylation of Aldehydes via a Conjugate Addition-Elimination Pathway
}

Key words

$\alpha$-alkylation

aldehydes

allylation

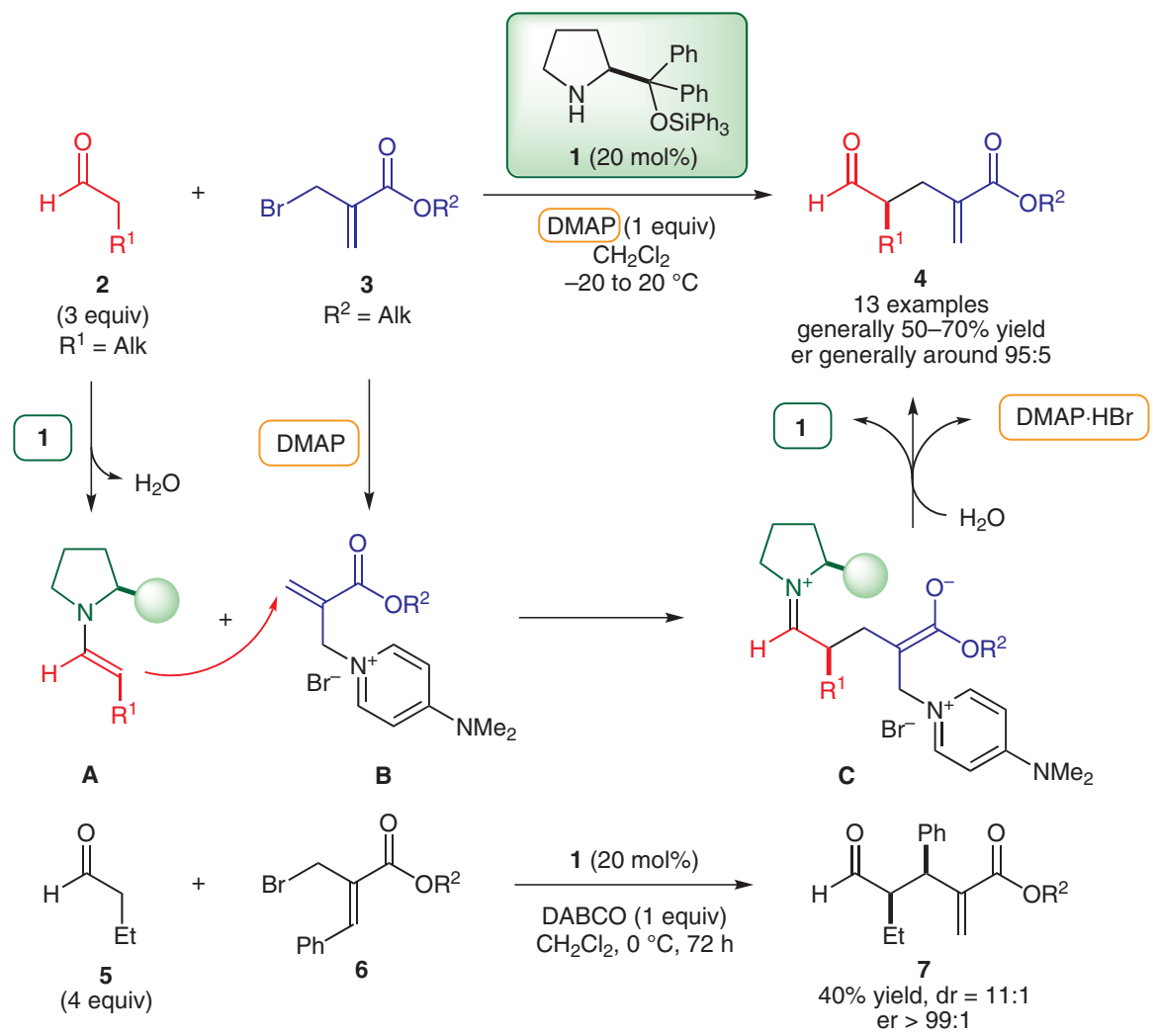
$\mathbf{1}$ delivered alkylation products $\mathbf{4}$ in moderate yields with high enantioselectivity. Using a more complex electrophile $\mathbf{6}$, product $\mathbf{7}$ was obtained with excellent enantioselectivity albeit in only $40 \%$ yield after three days. In addition to moderate yields, the main drawback of the reported method is the use of three equivalents of the aldehyde.

SYNFACTS Contributors: Benjamin List, Ilija Čorić Dol: 10.1055/s-0030-1259353; Reg-No.: B14710SF

Comment: The widely pursued catalytic asymmetric $\alpha$-alkylation of aldehydes has recently been advanced by using secondary amine catalysis via an intramolecular $\mathrm{S}_{\mathrm{N}} 2$ pathway, an intermolecular radical pathway, and also via $S_{N} 1$-type reactions. However, limitations of available methods with respect to suitable electrophiles prompted further research. In the current paper, Palomo and coworkers designed a system that circumvents catalyst alkylation probably by making it reversible. The crucial step of the reaction is based on a conjugate addition $(\mathbf{A}+\mathbf{B} \rightarrow \mathbf{C})$ rather than on a direct alkylation. DMAP serves a dual role: activating the electrophile via intermediate $\mathbf{B}$ (for example, see: Y.-C. Chen et al. Angew. Chem. Int. Ed. 2009, 48, 5737) and acting as a base to remove the liberated acid. 